\title{
Heated Intraperitoneal Chemotherapy in the Management of Advanced Ovarian Cancer
}

\author{
Andrea Jewell *, Megan McMahon and Dineo Khabele \\ Department of Obstetrics and Gynecology, Division of Gynecologic Oncology, \\ University of Kansas Medical Center, Kansas, KS 66160, USA; mmcmahon3@kumc.edu (M.M.); \\ dkhabele@kumc.edu (D.K.) \\ * Correspondence: AJEWELL@kumc.edu
}

Received: 5 June 2018; Accepted: 16 August 2018; Published: 1 September 2018

\begin{abstract}
Heated intraperitoneal chemotherapy (HIPEC) has several potential benefits. Higher doses of chemotherapy can be used with HIPEC because the plasma-peritoneal barrier results in little absorption into the blood stream. HIPEC offers higher peritoneal penetration in comparison to an intravenous (IV) regimen and does not have the traditional normothermic intraperitoneal (IP) regimen limitation of post-operative adhesions. Hyperthermia itself has cytotoxic effects and can potentiate antineoplastic effects of chemotherapy in part by increasing the depth of tumor penetration by up to $3 \mathrm{~mm}$. For the treatment of ovarian cancer, HIPEC has been evaluated in the recurrent setting with secondary cytoreduction. Recent studies, including a prospective trial, have evaluated its role in primary management of ovarian cancer. This review summarizes previous and ongoing studies regarding the use of HIPEC in the management of ovarian cancer.
\end{abstract}

Keywords: ovarian cancer; heated intraperitoneal chemotherapy (HIPEC); intraperitoneal chemotherapy (IP); cytoreductive surgery; secondary cytoreduction; interval cytoreduction

\section{Introduction}

Epithelial ovarian cancer (EOC) is the deadliest gynecologic malignancy [1]. The majority of women are diagnosed at advanced stage with widely metastatic peritoneal disease. Standard of care involves a combination of surgery and chemotherapy. The ability to surgically resect tumors with optimal cytoreduction surgery (CRS), ideally to no gross residual disease (R0), is an important positive prognostic factor [2]. Despite the improvements seen in median survival time with the current standard of radical tumor CRS and IV carboplatin and paclitaxel, long term survival rates for patients with advanced epithelial ovarian carcinoma remain disappointing and efforts continue to develop more effective primary therapy.

For most patients with EOC, the majority of disease burden is in the peritoneal cavity and can be quantified by the peritoneal cancer index (PCI) [3]. The PCI is a measure of the extent of disease burden in the peritoneal cavity. Due to this location, normothermic IP chemotherapy has been studied in prospective clinical trials in the post-operative treatment of primary EOC, and NCCN has noted the combined IV/IP regimen as preferred regimen for optimally cytoreduced Stage III EOC. In the setting of recurrence, treatment guidelines are determined by the time to recurrence and location of metastatic disease. HIPEC during CRS for EOC has been gaining more attention in the treatment of metastatic peritoneal disease. Specifically, HIPEC has more frequently been utilized in the recurrent setting with secondary CRS, but recent studies have evaluated its role in primary management of ovarian cancer. The aim of this article is to review previous and ongoing studies regarding the use of HIPEC in context of the overall use of IP chemotherapy for the treatment of EOC. 


\section{Normothermic Intraperitoneal Chemotherapy}

In normothermic IP chemotherapy, cisplatin and paclitaxel are injected into the patient's peritoneal cavity through an intraabdominal port. IP chemotherapy is administered in the post-operative period over a course of up to six cycles. Three large prospective randomized studies support the use of IP chemotherapy in the primary treatment of EOC. In the Gynecologic Oncology Group (GOG) 104 study, patients were randomized to two arms: the control arm of cisplatin and cyclophosphamide IV and the experimental arm of cisplatin IP and cyclophosphamide IV. While there was a statistically significant overall survival (OS) benefit to the IP regimen of 49 months in comparison to 41 months for the IV regimen, consensus was the benefits of IP chemo are not greater than the benefits of new agent paclitaxel [4]. In GOG 114, patients in the control arm received six cycles of cisplatin and paclitaxel IV with an OS of 52.5 months and the experimental arm received two cycles of carboplatin IV, followed by six cycles of cisplatin and paclitaxel IP with an OS of 63.2 months. Progression free survival (PFS) and OS were statistically significant, but were partially attributed to the addition of two extra cycles of chemotherapy in the IP arm [5].

GOG 172 influenced practice patterns in the United States. The IV/IP regimen of IP cisplatin and paclitaxel, plus IV paclitaxel demonstrated the longest median OS compared to IV carboplatin and paclitaxel in patients with optimally cytoreduced stage III ovarian cancer. The median PFS for the IV alone and IV/IP regimens was 18.3 and 23.8 months, respectively. The median OS for the IV and the IP regimens was 49.7 and 66.9 months, respectively. Due to chemotherapy-associated toxicities, only $42 \%$ of women on the IP regimen actually received six cycles of therapy, and $49 \%$ received three or fewer IP cycles [6]. Because the OS benefit outweighed the toxicity of the regimen, the NCI Clinical Announcement recognized the superiority of IP chemotherapy in the optimal disease setting [7].

In a follow up analysis of the mature data of GOG 114 and GOG 172 combined, an OS benefit remains significant for IP regimens after 10 years of follow up. This benefit in OS was most pronounced in patients who underwent optimal CRS to R0 treated with the IP regimen. Specifically, in GOG 172, the OS was 127 months in this subset of patients [8]. There was also a correlation noted between survival and the number of IP cycles completed in a separate follow up analysis [9].

Despite the favorable OS for IP chemotherapy, the IP cisplatin-based chemotherapy regimen has not been universally accepted as a standard treatment for EOC secondary to regimen toxicity and IP catheter access device problems. A more recent large prospective trial, GOG 252, compared weekly IV chemotherapy regimens to varying dose reduced IP regimens. All arms of the trial had bevacizumab added during treatment and as maintenance. No significant differences in PFS were observed between the three arms. In comparison to GOG 172, more patients were able to complete the IP regimens, but all arms had excessive toxicity. One concern in interpreting the data from GOG 252 is the addition of bevacizumab to all arms could have influenced the results and analysis [10]. With the inability to replicate the results from GOG 172 and the limitation to access IP chemotherapy outside of the tertiary setting, there has been increased interest in HIPEC as a treatment alternative in the primary and recurrent ovarian cancer setting.

\section{HIPEC}

In HIPEC, heated intraabdominal chemotherapy is administered at the time of CRS. HIPEC has several potential benefits. High-dose chemotherapy can be used because the plasma-peritoneal barrier results in little absorption into the blood stream [11,12]. In addition, there is higher peritoneal penetration in comparison to IV regimen, and HIPEC does not have the limitation of traditional IP regimen of post-operative adhesions $[13,14]$. Hyperthermia itself has cytotoxic effects and can increase the depth of tumor penetration by the chemotherapeutic agent up to $3 \mathrm{~mm}$ and moreover can potentiate its antineoplastic effects [15-18].

A major historic limitation to HIPEC is the previously reported morbidity and mortality and thus its use was often discouraged [19]. To proceed with HIPEC, CRS to R0, CC0 (non-visible disease remaining) or CC1 (less than $2.5 \mathrm{~mm}$ visible disease remaining) is required and involves radical 
and complex surgeries that are associated with higher complication rates. Currently, particularly in high-volume centers with HIPEC specialists, morbidity and mortality has drastically improved [20,21]. One large retrospective review of 694 patients, treated between 2005 and 2011, utilizing the American College of Surgeons National Surgical Quality Improvement Program (ACS NSQUIP) database, demonstrated a complication rate of $33 \%$ and 30-day mortality of $2.3 \%$, both rates consistent with outcomes for other major complex abdominal operations [21].

In EOC, HIPEC has been evaluated in the primary and recurrent setting. The majority of published data regarding this treatment modality is retrospective, but recently some prospective data has been published. Here we will review study outcomes with HIPEC in the management of primary and recurrent ovarian cancer as well as review ongoing trials.

\section{HIPEC in the Primary Treatment of Ovarian Cancer}

The largest prospective randomized clinical trial demonstrated a survival advantage for patients who received HIPEC, compared to standard IV chemotherapy, for the treatment of primary EOC. (Table 1) All patients received neoadjuvant chemotherapy after determining they were not eligible for primary CRS and had to have at least stable disease after receiving up-front IV chemotherapy. The control arm received standard IV chemotherapy before and after CRS (PFS = 10.7 months, $\mathrm{OS}=33.9$ months). The experimental arm received the same standard IV chemotherapy but also received HIPEC with cisplatin during CRS (PFS $=14.2$ months $(p=0.01), \mathrm{OS}=45.7$ months $(p=0.02)$ ). Over $90 \%$ of patients completed full six cycles of IV chemotherapy in both arms [22]. While the PFS and OS in this trial are shorter than the previous mentioned normothermic IP trials, it should be noted that this is a different patient population. The PFS and OS survival in the control arm of this trial are similar to established data in patients receiving NACT and interval CRS [23]. Similarly, a large retrospective study from Italy showed improved outcomes in patients who underwent HIPEC after having a complete or partial response to neoadjuvant IV chemotherapy in comparison to HIPEC at primary CRS. [24,25] In addition to standardizing the HIPEC procedure, the time of administration of HIPEC is another important factor.

Table 1. HIPEC primary trials.

\begin{tabular}{|c|c|c|c|c|c|}
\hline Author & Study type & $\mathbf{N}^{1}$ & Chemotherapy & PFS & OS \\
\hline Van Driel, et al. [23] & Prospective & 245 & Cisplatin & 14.2 months & 45.7 months \\
\hline Bakrin, et al. [26] & $\begin{array}{c}\text { Retrospective } \\
\text { cohort }\end{array}$ & 92 & Cisplatin $(80 \%)^{2}$ & $\mathrm{n} / \mathrm{a}$ & $\begin{array}{l}\text { CC0: } 41.5 \\
\text { months }\end{array}$ \\
\hline Gonzalez Bayon, et al. [27] & Prospective & 15 & $\begin{array}{l}\text { Cisplatin and } \\
\text { Doxorubicin }\end{array}$ & $\mathrm{n} / \mathrm{a}$ & 77.8 months \\
\hline Cascales-Campos, et al. [28] & $\begin{array}{l}\text { Retrospective } \\
\text { Series }\end{array}$ & 52 & Paclitaxel & $\begin{array}{c}1 \text { year: } 81 \% \\
3 \text { years: } 63 \%\end{array}$ & $\mathrm{n} / \mathrm{a}$ \\
\hline Bae, et al. [29] & $\begin{array}{l}\text { Retrospective } \\
\text { Case Control }\end{array}$ & 67 & $\begin{array}{c}\text { Carboplatin or } \\
\text { Paclitaxel }\end{array}$ & 3 years: $56.3 \%$ & 3 years: $66.1 \%$ \\
\hline
\end{tabular}

\footnotetext{
${ }^{1}$ : Number of HIPEC patients in trial. ${ }^{2}$ : Chemotherapy included in analysis: included cisplatin, doxorubicin,
} oxaliplatin, mitomycin, cisplatin and mitomycin, and cisplatin and doxorubicin

A retrospective cohort study from France looked at 92 patients receiving HIPEC for primary EOC treatment. The majority $(60.8 \%)$ received consolidation HIPEC treatment after receiving 6-9 cycles of IV carboplatin and paclitaxel. The rest received HIPEC at primary CRS (13\%) and at interval CRS $(26.1 \%$.) The majority of patients received cisplatin HIPEC $(80.4 \%$,) but $35.9 \%$ did receive a second agent with HIPEC, either doxorubicin (19.6\%) or mitomycin (18.5\%). Significant to survival were timing of HIPEC, peritoneal cancer index (PCI), and R0 CRS. Longest median OS was seen in the primary CRS group at 52.7 months, followed by interval CRS at 36.5 months and then consolidation HIPEC at 33.4 months $(p=0.03$.) Of all primary HIPEC patients, those able to be optimally cytoreduced to less than 2.5 millimeters $(\mathrm{mm})$ had a median survival of 41.5 months compared to 21.2 months in those 
with residual disease greater than $2.5 \mathrm{~mm}(p<0.01)$ [26]. Again, this is a different patient population than was evaluated in previous normothermic IP trials; therefore we cannot make direct comparisons.

A trial from Spain prospectively evaluated a smaller series of primary, first recurrence and second recurrence EOC patients. Fifteen patients received HIPEC in the primary setting, and all received neoadjuvant chemotherapy. All patients received a combination of cisplatin and doxorubicin chemotherapy during HIPEC. The majority $(73 \%)$ of patients were optimally cytoreduced to no gross residual cancer, and the median OS was remarkably 77.8 months in this patient population. This survival is similar to previously published normothermic IP chemotherapy data, but, again, we cannot compare such a small series of patients with different parameters [27].

Another larger trial from Spain was a case control series evaluating HIPEC in both the primary and interval CRS setting. Twenty three patients underwent primary cytoreduction with HIPEC and 29 patients underwent neoadjuvant chemotherapy and then interval CRS with HIPEC. All patients had CC0 CRS to no visible residual disease. Interestingly, the PCI was significantly higher in the HIPEC arm meaning that these patients had a larger tumor burden at the beginning of surgery. Also, a higher rate of bowel anastomosis and peritoneal stripping was observed in the HIPEC arm, but these cases were performed after data was published showing that aggressive CRS is associated with improved survival. In contrast, most of the control arm cases were performed before this time period. While the ovarian histology was not categorized, they did identify tumor grade. Up to $30 \%$ of tumors in the HIPEC arm were low grade which is a higher than typical ratio. No information was provided of how many cycles of IV chemotherapy was completed. While unable to complete analysis of OS, the disease free survival (DFS) was followed at 1, 2 and 3 years. In the control arm, respectively, the DFS was $66 \%$, $33 \%, 18 \%$; and in the HIPEC arm, the DFS was $81 \%, 67 \%, 63 \%(p<0.01)$. It was noted that the survival benefit of HIPEC was not significant in undifferentiated tumors [28].

A retrospective review from South Korea evaluated the role of HIPEC as consolidation treatment at the end of primary IV chemotherapy. All patients underwent primary CRS (included both CC0 and suboptimal patients in analysis) then received adjuvant IV chemotherapy. Patients then underwent a planned secondary CRS. There were 29 patients in the control arm and 67 in the HIPEC arm. HIPEC patients received either single agent carboplatin or paclitaxel at time of CRS. Early stage EOC did not show a survival advantage with HIPEC treatment. However, for stage III control and HIPEC patients, PFS at 3 years was, respectively, $16.7 \%$ and $56.3 \%(p<0.01)$ and OS $32.8 \%$ and $66.1 \%(p<0.01$.) There was no survival difference between the carboplatin HIPEC and paclitaxel HIPEC subgroups. A higher hematologic toxicity was seen in the carboplatin HIPEC arm, however [29].

\section{HIPEC in the Treatment of Recurrent Ovarian Cancer}

Substantially more studies have been published regarding the use of HIPEC in the management of recurrent ovarian cancer. Although, a significant amount are retrospective, evaluating a small series of patients or inconsistent with patient parameters and HIPEC dosing. Platinum agents are one of the most commonly used during HIPEC for ovarian cancer, but the dose varies in trials. A phase I trial was published regarding the maximum tolerated dose of (MTD) of cisplatin for HIPEC at time of first recurrence (Table 2). The MTD established was $100 \mathrm{mg} / \mathrm{m}^{2}$ with $25 \%$ of patients experiencing $\mathrm{Gr} 3-4$ toxicity. Notably no severe hematologic toxicity at this dose, and over $90 \%$ of patients completed all 6 cycles of adjuvant IV chemotherapy. The median PFS of 13.6 months was comparable to previously published PFS in recurrent ovarian patients treated with IV chemotherapy alone. Peritoneal platinum concentration was significantly elevated in comparison to plasma levels, and platinum DNA adducts were found in tumor biopsies after HIPEC confirming cytotoxic activity immediately after a single dose of cisplatin. A Phase II trial is currently open to further evaluate the efficacy of this dose and regimen [30].

The retrospective cohort study from France also looked at the role of HIPEC in recurrent ovarian cancer. The paper included 247 chemo-sensitive (defined as a recurrence interval of greater than six months after completing IV chemotherapy) and 223 chemo-resistant (defined as a recurrence interval of 
less than six months) EOC patients. Similarly, the majority of patients received cisplatin HIPEC $(75.3 \%$, but $36.4 \%$ did receive a second agent with HIPEC, either doxorubicin $(28.1 \%)$ or mitomycin $(9.1 \%)$. Significant to survival were lower PCI and CCO CRS. Longest median OS was in patients with PCI score of $0-8,59.3$ months, followed by patients achieving CC0 CRS, 51.5 months. Interestingly, there was not a significant difference in survival between the chemo-sensitive (42.2 months) and chemo-resistant (48.0 months) subgroups. This could signify the benefit of hyperthermia in chemo-resistant tumors [26]. Other studies, however, have shown no benefit to HIPEC in chemo-resistant patients, and this needs to be further evaluated [25].

The previous trial from Spain prospectively evaluated a smaller series of primary, as well as 19 first recurrence and eight second recurrence EOC patients. All patients received a combination of cisplatin and doxorubicin chemotherapy during HIPEC. The majority $(74 \%, 75 \%$ respectively) of patients were optimally CRS to CC0. The median OS was 62.8 months in the first recurrence group and 35.7 months in the second recurrence group. There was no difference in survival between patients reduced to no gross residual disease (CC0) and those with less than $2.5 \mathrm{~mm}$ of disease (CC1) [27]. The survival in this study is similar to previously published data of patients being treated with secondary surgery for recurrent ovarian cancer [31,32].

In a second trial from Spain, a case control review was performed on chemo-sensitive disease at first recurrence. Chemo-sensitive defined as recurrence greater than 12 months from completion of treatment. Twenty two patients underwent CRS solely and 39 patients underwent CRS with HIPEC. All patients included underwent CCO CRS to no residual disease. Median PFS was 22 months in the CRS alone group and 21 months in the CRS with HIPEC group. While both groups were optimally cytoreduced, the HIPEC had a significantly higher PCI score. This could indicate a more aggressive group of tumors and explain the similar PFS even with the addition of HIPEC. Also, paclitaxel rather than a platinum agent was used in the trial, and, due to the cell cycle dependent mechanism of action, it was theorized that it may not be the most effective agent for use during HIPEC. Reassuringly, both groups had similar post-operative toxicity [33].

Table 2. HIPEC recurrent trials in ovarian cancer.

\begin{tabular}{|c|c|c|c|c|c|}
\hline Author & Study type & $\mathbf{N}^{1}$ & Chemotherapy & PFS & os \\
\hline Zivanovic et al. [30] & $\begin{array}{c}\text { Phase I } \\
\text { prospective }\end{array}$ & 12 & Cisplatin & 13.6 months & $\mathrm{n} / \mathrm{a}$ \\
\hline Bakrin et al. [26] & $\begin{array}{l}\text { Retrospective } \\
\text { Cohort }\end{array}$ & 470 & Cisplatin $(76 \%)^{2}$ & $\mathrm{n} / \mathrm{a}$ & $\begin{array}{c}\text { CC0: } 51.5 \\
\text { months }\end{array}$ \\
\hline Gonzalez Bayon et al. [27] & Prospective & 27 & $\begin{array}{l}\text { Cisplatin and } \\
\text { Doxorubicin }\end{array}$ & $\mathrm{n} / \mathrm{a}$ & $\begin{array}{l}\text { 1st recurrence: } \\
62.8 \text { months } \\
\text { 2nd recurrence: } \\
35.7 \text { months }\end{array}$ \\
\hline Cascales-Campos et al. [28] & Case control & 39 & Paclitaxel & 21 months & $\mathrm{n} / \mathrm{a}$ \\
\hline Fagotti et al. [34] & Case Control & 30 & Oxaliplatin & 26 months & 5 years: $42.7 \%$ \\
\hline Spiliotis et al. [35] & Prospective & 60 & Multiagent $^{3}$ & $\mathrm{n} / \mathrm{a}$ & 26.7 months \\
\hline
\end{tabular}

${ }^{1}$ : Number of HIPEC patients in trial. ${ }^{2}$ : Chemotherapy included in analysis: included cisplatin, doxorubicin, oxaliplatin, mitomycin, cisplatin and mitomycin, and cisplatin and doxorubicin. ${ }^{3}$ : Chemo-sensitive-Cisplatin and paclitaxel; Chemo-resistant-Doxorubicin with paclitaxel or mitomycin

A similar patient population was studied in Italy. A case control study with 37 patient controls receiving either CRS and IV chemotherapy (13 patients) or IV chemotherapy alone (24 patients) versus 30 patients undergoing CRS and HIPEC. All patients were experiencing a first recurrence, and the initial PFS was similar in both the control and case arms. The only significant difference between the arms was pattern of recurrence. The control arm had significantly more patients with single nodule or localized recurrence. All control patients achieved CC0 CRS, and 96.7\% of HIPEC patients achieved CC0 CRS. PFS was 15 months in the control arm and 26 months in the HIPEC arm. Interestingly, over half of the HIPEC patients had a longer secondary PFS after HIPEC than the primary PFS after 
initial treatment. The HIPEC patients had significantly longer OS, secondary PFS, and deaths than the control group [34].

A prospective trial from Greece evaluated the role of HIPEC at first recurrence. Sixty patients were randomized to each arm; CRS followed by IV chemotherapy versus CRS with HIPEC followed by IV chemotherapy. The trial included both chemo-sensitive and chemo-resistant patients. The HIPEC chemo-sensitive patients were treated with cisplatin and paclitaxel during CRS and the chemo-resistant were treated with doxorubicin and paclitaxel or mitomycin. Mean OS was 26.7 months in the HIPEC group versus 13.4 months in the control group $(p<0.01$.) The OS was similar in both the HIPEC chemo-sensitive (26.8 months) and chemo-resistant (26.6 months) subgroups. In comparison, the OS was significantly different in the control arm chemo-sensitive (15.2 months) and chemo-resistant (10.2 months) subgroups $(p<0.01$.) Both arms achieved similar rates of CC0 CRS. However, the overall survival in the HIPEC CC0 group was significantly higher (30.9 months) than the control CC0 group (16.9 months) [35].

\section{Discussion}

Ovarian cancer is the deadliest gynecologic malignancy in the United States. Normothermic IP chemotherapy for primary EOC has a known benefit in the optimal CRS setting. Unfortunately, widespread use has not occurred due to concern for toxicity and patient access to tertiary care centers. Due to these concerns, there is interest in HIPEC therapy for the management of primary and recurrent EOC.

The largest HIPEC study published to date was in the setting of primary EOC. A survival benefit in patients undergoing interval CRS was found with the addition of HIPEC, and there was no difference in toxicity between the control and HIPEC arms [22]. A critique of the study is that it did not have an IP chemotherapy arm for comparison. The role of normothermic IP chemotherapy is unclear in the interval CRS patient population. A phase II randomized trial, OV21/PETROC, was completed and the IP regimen was found to be well tolerated with reasonable toxicity and no reduction in QOL. There was a noted decrease in progression of disease at nine months in the IP group, however, as the study was underpowered, there was no difference found in PFS and OS between the IV and IP arms [36].

More studies have been published in the recurrent setting, however, most are small and retrospective. A primary critique of HIPEC therapy in EOC is that there is not a standardized regimen. Platinum agents, specifically cisplatin, are frequently used but at varying doses. The phase I trial published defining cisplatin $100 \mathrm{mg} / \mathrm{m}^{2}$ as the maximum tolerated dose (MTD) will be important to consider when moving forward with designing HIPEC trials in EOC. This was the same dose utilized in the above mentioned primary EOC prospective trial.

Along with varying doses in the recurrent setting, there were varying responses to HIPEC therapy. Prolonged disease free intervals have been shown in both the first and second recurrence settings. Interestingly, some trials have shown similar response in both chemo-sensitive and chemo-resistant recurrences [26]. In one study, the HIPEC arm of patients had a significantly higher PCI at time of CRS yet similar survival to the control arm [33]. A higher PCI is concerning for a more aggressive tumor biology, and could mean that the HIPEC played a role in the similar survival. Overall, there has been a positive significant survival response to HIPEC in the recurrent setting, but almost all published data is from small, retrospective studies.

A significant concern of HIPEC is the toxicity associated with the regimen. Prospective data published shows HIPEC to have similar toxicity to CRS followed by IV therapy [22,33]. Again, these are a limited number of studies, and further evaluation of morbidity and mortality needs to be performed. Another concern of HIPEC therapy is the increased cost associated with frequent ICU admissions and length of hospital stay. The inpatient IP regimen was found not cost effective in the short term in comparison to the traditional IV regimen, but when long term survival analysis was considered it became more cost effective due to the improved survival [37]. There has been no cost analysis performed for HIPEC in EOC. The addition of targeted or immunotherapies to IV regimens 
is another popular treatment option being considered. The addition of bevacizumab has been found not cost effective when considering all advanced stage EOC receiving IV therapy [38]. However, the cost effectiveness of bevacizumab was improved when looking at a subgroup of patients [39]. This illustrates the significance of identifying appropriate patient populations for specific treatment modalities. It will be important in future trials to perform comparative cost analysis, especially if survival outcomes are similar.

\section{Conclusions}

In conclusion, there is now high quality prospective data suggesting a survival benefit to HIPEC therapy for patients undergoing primary treatment of EOC after receipt of neoadjuvant chemotherapy and optimal cytoreduction. Poorer quality data exists supporting its use in other clinical contexts such as recurrent disease. This treatment has not been studied in multiple clinical contexts, the regimen and toxicity management has not been standardized and HIPEC has not yet been compared to other standard treatments such as normothermic IP chemotherapy. Therefore, the treatment of EOC with HIPEC outside of clinical trial would not be recommended. Further trials are undergoing (Table 3) and are needed to assess the appropriate patient population and mechanisms of action for HIPEC therapy.

Table 3. Ongoing randomized HIPEC trials in ovarian cancer.

\begin{tabular}{|c|c|c|c|c|c|c|}
\hline Country & PI & Phase & Time Point & Sample Size & Chemotherapy & $\begin{array}{c}\text { Clinicaltrials.gov } \\
\text { Identifier }\end{array}$ \\
\hline South Korea & Chang & $\mathrm{N} / \mathrm{A}$ & Primary & 204 & Paclitaxel & NCT03448354 \\
\hline United States & Momeni & 1 & Recurrent & 20 & Carboplatin & NCT02672098 \\
\hline Italy & Not provided & $\mathrm{N} / \mathrm{A}$ & Recurrent & 158 & Cisplatin & NCT01538785 \\
\hline Spain & Villarejo Campos & 3 & $\begin{array}{l}\text { Primary or } \\
\text { recurrent }\end{array}$ & 94 & Paclitaxel & NCT02681432 \\
\hline China & Cui & 3 & $\begin{array}{l}\text { Primary or } \\
\text { recurrent }\end{array}$ & 214 & $\begin{array}{l}\text { Paclitaxeland } \\
\text { cisplatin }\end{array}$ & NCT03373058 \\
\hline United States & Jewell & 2 & Primary & 20 & Cisplatin & NCT03321188 \\
\hline Italy, Germany & Ansaloni & 3 & Primary & 94 & $\begin{array}{l}\text { Cisplatin and } \\
\text { paclitaxel }\end{array}$ & NCT01628380 \\
\hline Mexico & Salcedo-Hernandez & 2 & Primary & 100 & $\begin{array}{l}\text { Cisplatin and } \\
\text { doxorubicin }\end{array}$ & NCT03275194 \\
\hline Spain & Villarejo Campos & 3 & $\begin{array}{l}\text { Primary or } \\
\text { recurrent }\end{array}$ & 32 & Cisplatin & NCT02328716 \\
\hline $\begin{array}{c}\text { Belgium, France, } \\
\text { Spain }\end{array}$ & Classe & 3 & Recurrent & 444 & Cisplatin & NCT01376752 \\
\hline France & not provided & 3 & Recurrent & 220 & Cisplatin & NCT03220932 \\
\hline United States & Zivanovic & 2 & Recurrent & 98 & Carboplatin & NCT01767675 \\
\hline India & Solanki & $\mathrm{N} / \mathrm{A}$ & $\begin{array}{l}\text { Primary or } \\
\text { recurrent }\end{array}$ & 150 & Not provided & NCT02754115 \\
\hline United States & Sardi & 2 & Primary & 48 & Carboplatin & NCT02124421 \\
\hline United States & Kelly & 2 & $\begin{array}{l}\text { Primary or } \\
\text { recurrent }\end{array}$ & 40 & Carboplatin & NCT03188432 \\
\hline United States & Dellinger & 1 & $\begin{array}{l}\text { Primary or } \\
\text { recurrent }\end{array}$ & 5 & Cisplatin & NCT01970722 \\
\hline Norway & Flatmark & Observational & $\begin{array}{l}\text { Primary or } \\
\text { recurrent }\end{array}$ & 200 & Not provided & NCT02073500 \\
\hline Belgium & Ceelen & 2 & $\begin{array}{l}\text { Primary or } \\
\text { recurrent }\end{array}$ & 48 & Cisplatin & NCT02567253 \\
\hline United States & Lilja & 2 & Recurrent & 200 & Cisplatin & NCT02349958 \\
\hline France & Bereder & N/A & $\begin{array}{l}\text { Primary or } \\
\text { recurrent }\end{array}$ & 44 & Not provided & NCT02803515 \\
\hline
\end{tabular}

Author Contributions: Conceptualization, A.J. and D.K.; Writing-Original Draft Preparation, M.M. and A.J.; Writing-Review \& Editing, M.M., A.J. and D.K.; Supervision, A.J. and D.K.

Funding: This research received no external funding.

Conflicts of Interest: The authors declare no conflict of interest. 


\section{References}

1. Siegel, R.L.; Miller, K.D.; Jemal, A. Cancer statistics, 2018. CA Cancer J. Clin. 2018, 68, 7-30. [CrossRef] [PubMed]

2. Chang, S.J.; Hodeib, M.; Chang, J.; Bristow, R.E. Survival impact of complete cytoreduction to no gross residual disease for advanced-stage ovarian cancer: A meta-analysis. Gynecol. Oncol. 2013, 130, 493-498. [CrossRef] [PubMed]

3. Jayson, G.C.; Kohn, E.C.; Kitchener, H.C.; Ledermann, J.A. Ovarian cancer. Lancet 2014, 384, $1376-1388$. [CrossRef]

4. Alberts, D.S.; Liu, P.Y.; Hannigan, E.V.; O’Toole, R.; Williams, S.D.; Young, J.A.; Franklin, E.W. Intraperitoneal cisplatin plus intravenous cyclophosphamide versus intravenous cisplatin plus intravenous cyclophosphamide for stage III ovarian cancer. N. Engl. J. Med. 1996, 335, 1950-1955. [CrossRef] [PubMed]

5. Markman, M.; Bundy, B.N.; Alberts, D.S.; Fowler, J.M.; Clark-Pearson, D.L.; Carson, L.F.; Wadler, S.; Sickel, J. Phase III trial of standard-dose intravenous cisplatin plus paclitaxel versus moderately high-dose carboplatin followed by intravenous paclitaxel and intraperitoneal cisplatin in small-volume stage III ovarian carcinoma: An intergroup study of the Gynecologic Oncology Group, Southwestern Oncology Group, and Eastern Cooperative Oncology Group. J. Clin. Oncol. 2001, 19, 1001-1007. [PubMed]

6. Armstrong, D.K.; Bundy, B.; Wenzel, L.; Huang, H.Q.; Baergen, R.; Lele, S.; Copeland, L.J. Intraperitoneal cisplatin and paclitaxel in ovarian cancer. N. Engl. J. Med. 2006, 354, 34-43. [CrossRef] [PubMed]

7. NCI Clinical Announcement on Intraperitoneal Chemotherapy in Ovarian Cancer. 2006. Available online: https:/ / ctep.cancer.gov/highlights/20060105_ovarian.htm (accesssed on 20 August 2018).

8. Landrum, L.M.; Java, J.; Mathews, C.A.; Lanneau, G.S., Jr.; Copeland, L.J.; Armstrong, D.K.; Walker, J.L. Prognostic factors for stage III epithelial ovarian cancer treated with intraperitoneal chemotherapy: A Gynecologic Oncology Group study. Gynecol. Oncol. 2013, 130, 12-18. [CrossRef] [PubMed]

9. Tewari, D.; Java, J.J.; Salani, R.; Armstrong, D.K.; Markman, M.; Herzog, T.; Monk, B.J.; Chan, J.K. Long-term survival advantage and prognostic factors associated with intraperitoneal chemotherapy treatment in advanced ovarian cancer: A gynecologic oncology group study. J. Clin. Oncol. 2015, 33, 1460-1466. [CrossRef] [PubMed]

10. Walker, J.; Brady, M.F.; DiSilvestro, P.A.; Fujiwara, K.; Alberts, D.; Zheng, W.; Tewari, K.; Cohn, D.E.; Powell, M.; Van Le, L.; et al. A phase III clinical trial of bevacizumab with IV versus IP chemotherapy in ovarian, fallopian tube, and primary peritoneal carcinoma. NCI-supplied agent: Bevacizumab. NCT01167712, a GOG/NRG trial (GOG 252), in Society of Gynecologic Oncologists. In Proceedings of the 2016 Annual Meeting on Women's Cancer, San Diego, CA, USA, 21 March 2016.

11. Sugarbaker, P.H.; Graves, T.; DeBruijn, E.A.; Cunliffe, W.J.; Mullins, R.E.; Hull, W.E.; Oliff, L.; Schlag, P. Early postoperative intraperitoneal chemotherapy as an adjuvant therapy to surgery for peritoneal carcinomatosis from gastrointestinal cancer: Pharmacological studies. Cancer Res. 1990, 50, 5790-5794. [PubMed]

12. Katz, M.H.; Barone, R.M. The rationale of perioperative intraperitoneal chemotherapy in the treatment of peritoneal surface malignancies. Surg. Oncol. Clin. N. Am. 2003, 12, 673-688. [CrossRef]

13. Sun, X.; Li, X.F.; Russell, J.; Xing, L.; Urano, M.; Li, G.C.; Humm, J.L.; Ling, C.C. Changes in tumor hypoxia induced by mild temperature hyperthermia as assessed by dual-tracer immunohistochemistry. Radiother. Oncol. 2008, 88, 269-276. [CrossRef] [PubMed]

14. Petrillo, M.; De Iaco, P.; Cianci, S.; Perrone, M.; Costantini, B.; Ronsini, C.; Scambia, G.; Fagotti, A. Long-Term Survival for Platinum-Sensitive Recurrent Ovarian Cancer Patients Treated with Secondary Cytoreductive Surgery Plus Hyperthermic Intraperitoneal Chemotherapy (HIPEC). Ann. Surg. Oncol. 2016, 23, 1660-1665. [CrossRef] [PubMed]

15. Teicher, B.A.; Kowal, C.D.; Kennedy, K.A.; Sartorelli, A.C. Enhancement by hyperthermia of the in vitro cytotoxicity of mitomycin C toward hypoxic tumor cells. Cancer Res. 1981, 41, 1096-1099. [PubMed]

16. El-Kareh, A.W.; Secomb, T.W. A theoretical model for intraperitoneal delivery of cisplatin and the effect of hyperthermia on drug penetration distance. Neoplasia 2004, 6, 117-1127. [CrossRef] [PubMed]

17. VanderWaal, R.; Thampy, G.; Wright, W.D.; Roti Roti, J.L. Heat-induced modifications in the association of specific proteins with the nuclear matrix. Radiat. Res. 1996, 145, 746-753. [CrossRef] [PubMed]

18. Roti Roti, J.L.; Kampinga, H.H.; Malyapa, R.S.; Wright, W.D.; vanderWaal, R.P.; Xu, M. Nuclear matrix as a target for hyperthermic killing of cancer cells. Cell Stress Chaperones 1998, 3, 245-255. [CrossRef] 
19. Chua, T.C.; Yan, T.D.; Saxena, A.; Morris, D.L. Should the treatment of peritoneal carcinomatosis by cytoreductive surgery and hyperthermic intraperitoneal chemotherapy still be regarded as a highly morbid procedure? A systematic review of morbidity and mortality. Ann. Surg. 2009, 249, 900-907. [CrossRef] [PubMed]

20. Voron, T.; Eveno, C.; Jouvin, I.; Beaugerie, A.; Lo Dico, R.; Dagois, S.; Soyer, P.; Pocard, M. Cytoreductive surgery with a hyperthermic intraperitoneal chemotherapy program: Safe after 40 cases, but only controlled after 140 cases. Eur. J. Surg. Oncol. 2015, 41, 1671-1677. [CrossRef] [PubMed]

21. Jafari, M.D.; Halabi, W.J.; Stamos, M.J.; Nguyen, V.Q.; Carmichael, J.C.; Mills, S.D.; Pigazzi, A. Surgical outcomes of hyperthermic intraperitoneal chemotherapy: Analysis of the american college of surgeons national surgical quality improvement program. JAMA Surg. 2014, 149, 170-175. [CrossRef] [PubMed]

22. Van Driel, W.J.; Koole, S.N.; Sonke, G.S. Hyperthermic Intraperitoneal Chemotherapy in Ovarian Cancer. N. Engl. J. Med. 2018, 378, 1363-1364. [CrossRef] [PubMed]

23. Vergote, I.; Trope, C.; Amant, F.; Kristensen, G.; Ehlen, T.; Johnson, N.; Verheijen, R.; van der Burg, M.; Lacave, A.; Benedettie Panici, P.; et al. Neoadjuvant chemotherapy or primary surgery in stage IIIC or IV ovarian cancer. N. Engl. J. Med. 2010, 363, 943-953. [CrossRef] [PubMed]

24. Kireeva, G.S.; Gafton, G.I.; Guseynov, K.D.; Senchik, K.Y.; Belyaeva, O.A.; Bespalov, V.G.; Panchenko, A.V.; Maydin, M.A.; Belyaev, A.M. HIPEC in patients with primary advanced ovarian cancer: Is there a role? A systematic review of short- and long-term outcomes. Surg. Oncol. 2018, 27, 251-258. [CrossRef] [PubMed]

25. Di Giorgio, A.; De Iaco, P.; De Simone, M.; Garofalo, A.; Scambia, G.; Pinna, A.D.; Verdecchia, G.M. Cytoreduction (Peritonectomy Procedures) Combined with Hyperthermic Intraperitoneal Chemotherapy (HIPEC) in Advanced Ovarian Cancer: Retrospective Italian Multicenter Observational Study of 511 Cases. Ann. Surg. Oncol. 2017, 24, 914-922. [CrossRef] [PubMed]

26. Bakrin, N.; Bereder, J.M.; Decullier, E.; Classe, J.M.; Msika, S.; Lorimier, G.; Abboud, K. Peritoneal carcinomatosis treated with cytoreductive surgery and Hyperthermic Intraperitoneal Chemotherapy (HIPEC) for advanced ovarian carcinoma: A French multicentre retrospective cohort study of 566 patients. Eur. J. Surg. Oncol. 2013, 39, 1435-1443. [CrossRef] [PubMed]

27. Gonzalez Bayon, L.; Steiner, M.A.; Vasquez Jimenez, W.; Asencio, J.M.; Alvarez de Sierra, P.; Atahualpa Arenas, F.; Rodriguez del Campo, J.; Garcia Sabrido, J.L. Cytoreductive surgery and hyperthermic intraperitoneal chemotherapy for the treatment of advanced epithelial ovarian carcinoma: Upfront therapy, at first recurrence, or later? Eur. J. Surg. Oncol. 2013, 39, 1109-1115. [CrossRef] [PubMed]

28. Cascales-Campos, P.A.; Gil, J.; Gil, E.; Feliciangeli, E.; Gonzalez-Gil, A.; Parrilla, J.J.; Parrilla, P. Treatment of microscopic disease with hyperthermic intraoperative intraperitoneal chemotherapy after complete cytoreduction improves disease-free survival in patients with stage IIIC/IV ovarian cancer. Ann. Surg. Oncol. 2014, 21, 2383-2389. [CrossRef] [PubMed]

29. Bae, J.H.; Lee, J.M.; Ryu, K.S.; Lee, Y.S.; Park, Y.G.; Hur, S.Y.; Ahn, W.S.; Namkoong, S.E. Treatment of ovarian cancer with paclitaxel- or carboplatin-based intraperitoneal hyperthermic chemotherapy during secondary surgery. Gynecol. Oncol. 2007, 106, 193-200. [CrossRef] [PubMed]

30. Zivanovic, O.; Abramian, A.; Kullmann, M.; Fuhrmann, C.; Coch, C.; Hoeller, T.; Ruehs, H. HIPEC ROC I: A phase I study of cisplatin administered as hyperthermic intraoperative intraperitoneal chemoperfusion followed by postoperative intravenous platinum-based chemotherapy in patients with platinum-sensitive recurrent epithelial ovarian cancer. Int. J. Cancer 2015, 136, 699-708. [CrossRef] [PubMed]

31. Benedetti Panici, P.; De Vivo, A.; Bellati, F.; Manci, N.; Perniola, G.; Basile, S.; Muzii, L.; Angioli, R. Secondary cytoreductive surgery in patients with platinum-sensitive recurrent ovarian cancer. Ann. Surg. Oncol. 2007, 14, 1136-1142. [CrossRef] [PubMed]

32. Tian, W.J.; Jiang, R.; Cheng, X.; Tang, J.; Xing, Y.; Zang, R.Y. Surgery in recurrent epithelial ovarian cancer: Benefits on Survival for patients with residual disease of $0.1-1 \mathrm{~cm}$ after secondary cytoreduction. J. Surg. Oncol. 2010, 101, 244-250. [CrossRef] [PubMed]

33. Cascales-Campos, P.A.; Gil, J.; Feliciangeli, E.; Gil, E.; Gonzalez-Gil, A.; Lopez, V.; Ruiz-Pardo, J.; Nieto, A.; Parrilla, J.J.; Parrilla, P. The role of hyperthermic intraperitoneal chemotherapy using paclitaxel in platinum-sensitive recurrent epithelial ovarian cancer patients with microscopic residual disease after cytoreduction. Ann. Surg. Oncol. 2015, 22, 987-993. [CrossRef] [PubMed] 
34. Fagotti, A.; Costantini, B.; Petrillo, M.; Vizzielli, G.; Fanfani, F.; Margariti, P.A.; Turco, L.C.; Piovano, E.; Scambia, G. Cytoreductive surgery plus HIPEC in platinum-sensitive recurrent ovarian cancer patients: A case-control study on survival in patients with two year follow-up. Gynecol. Oncol. 2012, 127, 502-505. [CrossRef] [PubMed]

35. Spiliotis, J.; Halkia, E.; Lianos, E.; Kalantzi, N.; Grivas, A.; Efstathiou, E.; Giassas, S. Cytoreductive surgery and HIPEC in recurrent epithelial ovarian cancer: A prospective randomized phase III study. Ann. Surg. Oncol. 2015, 22, 1570-1575. [CrossRef] [PubMed]

36. Provencher, D.M.; Gallagher, C.J.; Parulekar, W.R.; Ledermann, J.A.; Armstrong, D.K.; Brundage, M.; Gourley, C. OV21/PETROC: A randomized Gynecologic Cancer Intergroup phase II study of intraperitoneal versus intravenous chemotherapy following neoadjuvant chemotherapy and optimal debulking surgery in epithelial ovarian cancer. Ann. Oncol. 2018, 29, 431-438. [CrossRef] [PubMed]

37. Havrilesky, L.J.; Secord, A.A.; Darcy, K.M.; Armstrong, D.K.; Kulasingam, S.; Group Gynecologic Oncology. Cost effectiveness of intraperitoneal compared with intravenous chemotherapy for women with optimally resected stage III ovarian cancer: A Gynecologic Oncology Group study. J. Clin. Oncol. 2008, 26, 4144-4150. [CrossRef] [PubMed]

38. Cohn, D.E.; Kim, K.H.; Resnick, K.E.; O’Malley, D.M.; Straughn, J.M., Jr. At what cost does a potential survival advantage of bevacizumab make sense for the primary treatment of ovarian cancer? A cost-effectiveness analysis. J. Clin. Oncol. 2011, 29, 1247-1251. [CrossRef] [PubMed]

39. Chan, J.K.; Herzog, T.J.; Hu, L.; Monk, B.J.; Kiet, T.; Blansit, K.; Kapp, D.S.; Yu, X. Bevacizumab in treatment of high-risk ovarian cancer-A cost-effectiveness analysis. Oncologist 2014, 19, 523-527. [CrossRef] [PubMed]

(C) 2018 by the authors. Licensee MDPI, Basel, Switzerland. This article is an open access article distributed under the terms and conditions of the Creative Commons Attribution (CC BY) license (http:// creativecommons.org/licenses/by/4.0/). 